\title{
NOTES
}

\section{Pyridinium Dicyanomethylide Initiated Copolymerization of Styrene and Methyl Methacrylate}

\author{
Prerna ShuKla and A. K. SRIVASTAVA* \\ Department of Chemistry, Harcourt Butler Technological Institute, \\ Kanpur-208 002, India
}

(Received December 15, 1988) KEY WORDS Pyridinium Dicyanomethylide / Alternating Copolymeriza-
tion / Styrene / Methyl Methacrylate / Kinetics / Dilatometry /

Polymer-ylide chemistry is a subject of growing interest. The work in this area was started mainly by Kondo et al. ${ }^{1,2}$ and involved photolytic generation of radicals. This laboratory also had reported potential applications of nitrogen ylides ${ }^{3-6}$ viz. picolinium and imidazolium as initiators for homo- and copolymerization of vinyl monomers.

Only a short time ago for the first time, the application of pyridinium dicyanomethylide as a radical initiator for homopolymerization of styrene (St) and methyl methacrylate (MMA) was reported by us. ${ }^{7,8}$ In the present paper, the application of pyridinium dicyanomethylide (PDMY) to obtain the alternating copolymer of styrene with methyl metacrylate, even in the absence of a lewis acid otherwise essential for radical initiation, is reported for the first time.

\section{EXPERIMENTAL}

MMA and St were purified by washing with $4 \% \mathrm{NaOH}$ and with distilled water to neutral and twice distilled before use. $\mathrm{Pu}$ rified solvents were used in the copolymerization. Tetracyanoethyleneoxide (Fluka AG No. 18509) and pyridine were used as such without further purification. The pyridinium dicyano- methylide, having following structure.<smiles></smiles>

was prepared according to the method by Linn et al. ${ }^{9}$ and was recrystallized twice with $50 \%$ ethanol-water mixture. It was insoluble in non-polar solvents like benzene and $\mathrm{CCl}_{4}$ but soluble in polar solvents like dimethylformamide (DMF) and dimethylsulphoxide (DMSO) and had a high melting point ${ }^{9}$ $\left(>250^{\circ} \mathrm{C}\right)$.

A solution containing the requisitic quantities of ylide and monomers in DMF as an inert solvent was injected into a modified dilometric apparatus, ${ }^{10}(0.2 \mathrm{~mm}$ capillary diam.). The reaction was carried out for $60 \mathrm{~min}$ at $85^{\circ} \mathrm{C} \pm 0.1{ }^{\circ} \mathrm{C}$ under nitrogen atmosphere in order to keep the percentage conversion low. The progress of the reaction, monitored as meniscus movement per unit volume per unit time with the help of a cathetometer, was converted into percentage conversion. The copolymer, precipitated with acidified methanol, was then treated with acetonitrile and cyclohexane to remove homopolymers, wherein undetectable weight loss was noticed. The co-

* To whom correspondence should be addressed. 
polymer so obtained was dissolved in benzene and reprecipitated with acidified methanol and then dried to a constant weight.

The rate of copolymerization $\left(R_{\mathrm{p}}\right)$ was calculated using the following equation ${ }^{10}$ :

$$
R_{\mathrm{p}}\left(\mathrm{moll}^{-1} \mathrm{~s}^{-1}\right)=0.7515 \times 10^{-3} \times \frac{U}{t}
$$

where,

$U=$ percentage conversion, and

$t=$ polymerization time in minutes

The intrinsic viscosity $[\eta]$ of the copolymers, determined in toluene at $30^{\circ} \mathrm{C}$ using Ubbelohde viscometer, was converted to the average degree of polymerization $\left(\bar{P}_{n}\right)$ as follows ${ }^{10}$ :

$$
[\eta]=5.75 \times 10^{-3} \bar{P}_{n} 0.746
$$

NMR spectroscopy (Varian 100 HA spectrometer, $\mathrm{CDCl}_{3}$ as the solvent and tetramethylsilane as the internal reference) has been used to characterize the copolymer.

\section{RESULTS AND DISCUSSION}

The results of radically initiated copolymerization of styrene and MMA are presented in Tables I-III and illustrated in Figures 1-4. The copolymerizations were associated with a short induction period $(5-6 \mathrm{~min})$.

\section{Effects of Ylide}

A study of Table I reveals that the rate of copolymerization is a direct function of [Ylide]

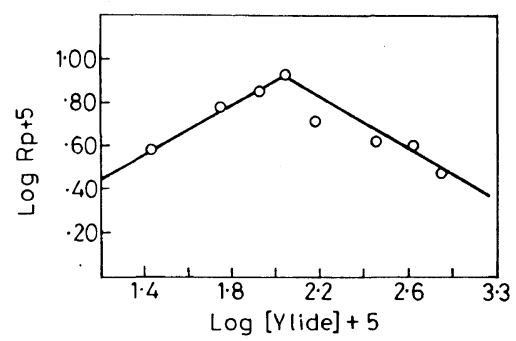

Figure 1. Graph for $\log$ rate of copolymerization plotted against the $\log$ concentration of pyridinium dicyanomethylide. $[\mathrm{MMA}]=1.44 \mathrm{moll}^{-1} ;[\mathrm{St}]=1.38$ moll $1^{-1}$; time $=60 \mathrm{~min}$; temperature $=85^{\circ} \mathrm{C} \pm 0.1^{\circ} \mathrm{C}$. from $2.7 \times 10^{-4}$ to $11.1 \times 10^{-4} \mathrm{moll}^{-1}$ but follows reverse suit thereafter upto $56.0 \times 10^{-4}$ moll ${ }^{-1}$ probably due to lower initiator efficiency which might be a consequence of primary radicals leading to their mutual annihilation to a certain extent. The order of

Table I. Copolymerization of styrene with MMA initiated by pyridinium dicyanomethylide ${ }^{a}$

\begin{tabular}{ccccc}
\hline \multirow{2}{*}{$\begin{array}{c}\text { Run } \\
\text { No. }\end{array}$} & {$[$ Ylide $] \times 10^{4}$} & Conversion & \multicolumn{1}{c}{$R_{\mathrm{p}} \times 10^{5}$} & \multirow{2}{*}{$\bar{P}_{n}$} \\
& $\mathrm{moll}^{-1}$ & percentage & $\mathrm{mol} \mathrm{1}^{-1} \mathrm{~s}^{-1}$ & \\
\hline 1 & 2.7 & 3.12 & 3.9 & 745 \\
2 & 5.6 & 5.0 & 6.2 & 623 \\
3 & 8.4 & 5.8 & 7.3 & 293 \\
4 & 11.1 & 6.8 & 8.5 & 200 \\
5 & 14.0 & 4.3 & 5.4 & - \\
6 & 28.0 & 3.5 & 4.3 & - \\
7 & 42.0 & 3.5 & 4.2 & - \\
8 & 56.0 & 2.5 & 3.1 & - \\
\hline
\end{tabular}

${ }^{\mathrm{a}}[$ Styrene $]=1.38 \mathrm{moll}^{-1} ;[\mathrm{MMA}]=1.44 \mathrm{moll}^{-1} ;$ time $=$ $60 \mathrm{~min}$; temperature $=85^{\circ} \mathrm{C} \pm 0.1^{\circ} \mathrm{C}$.

Table II. Effects of [MMA] on the rate of

\begin{tabular}{|c|c|c|c|}
\hline \multirow{2}{*}{$\begin{array}{l}\text { Run } \\
\text { No. }\end{array}$} & [MMA] & \multirow{2}{*}{$\begin{array}{l}\text { Conversion } \\
\text { percentage }\end{array}$} & \multirow{2}{*}{$\frac{R_{\mathrm{p}} \times 10^{5}}{\mathrm{moll}^{-1} \mathrm{~s}^{-1}}$} \\
\hline & $\mathrm{moll}^{-1}$ & & \\
\hline 1 & 0.36 & 1.24 & 1.5 \\
\hline 2 & 0.72 & 2.4 & 3.0 \\
\hline 3 & 1.08 & 3.17 & 3.9 \\
\hline 4 & 1.44 & 4.3 & 5.4 \\
\hline
\end{tabular}
copolymerization of styrene with $\mathrm{MMA}^{\mathrm{a}}$

${ }^{a}[$ Styrene $]=1.38 \mathrm{moll}^{-1} ;[$ Ylide $]=14.0 \times 10^{-4} \mathrm{moll}^{-1}$; time $=60 \mathrm{~min}$; temperature $=85^{\circ} \mathrm{C} \pm 0.1{ }^{\circ} \mathrm{C}$.

Table III. Effects of [Styrene] on the rate of

\begin{tabular}{|c|c|c|c|}
\hline \multirow{2}{*}{$\begin{array}{l}\text { Run } \\
\text { No. }\end{array}$} & [Styrene] & \multirow{2}{*}{$\begin{array}{l}\text { Conversion } \\
\text { percentage }\end{array}$} & \multirow{2}{*}{$\frac{R_{\mathrm{p}} \times 10^{5}}{\mathrm{moll}^{-1} \mathrm{~s}^{-1}}$} \\
\hline & $\mathrm{moll}^{-1}$ & & \\
\hline 1 & 0.34 & 1.2 & 1.5 \\
\hline 2 & 0.69 & 2.3 & 2.9 \\
\hline 3 & 1.04 & 3.1 & 3.9 \\
\hline 4 & 1.38 & 4.3 & 5.4 \\
\hline
\end{tabular}
copolymerization of styrene with $\mathrm{MMA}^{\mathrm{a}}$

${ }^{\mathrm{a}}[\mathrm{MMA}]=1.44 \mathrm{moll}^{-1} ;[$ Ylide $]=14.0 \times 10^{-4} \mathrm{moll}^{-1}$; time $=60 \mathrm{~min}$; temperature $=85^{\circ} \mathrm{C} \pm 0.1^{\circ} \mathrm{C}$.

Polymer J., Vol. 21, No. 11, 1989 


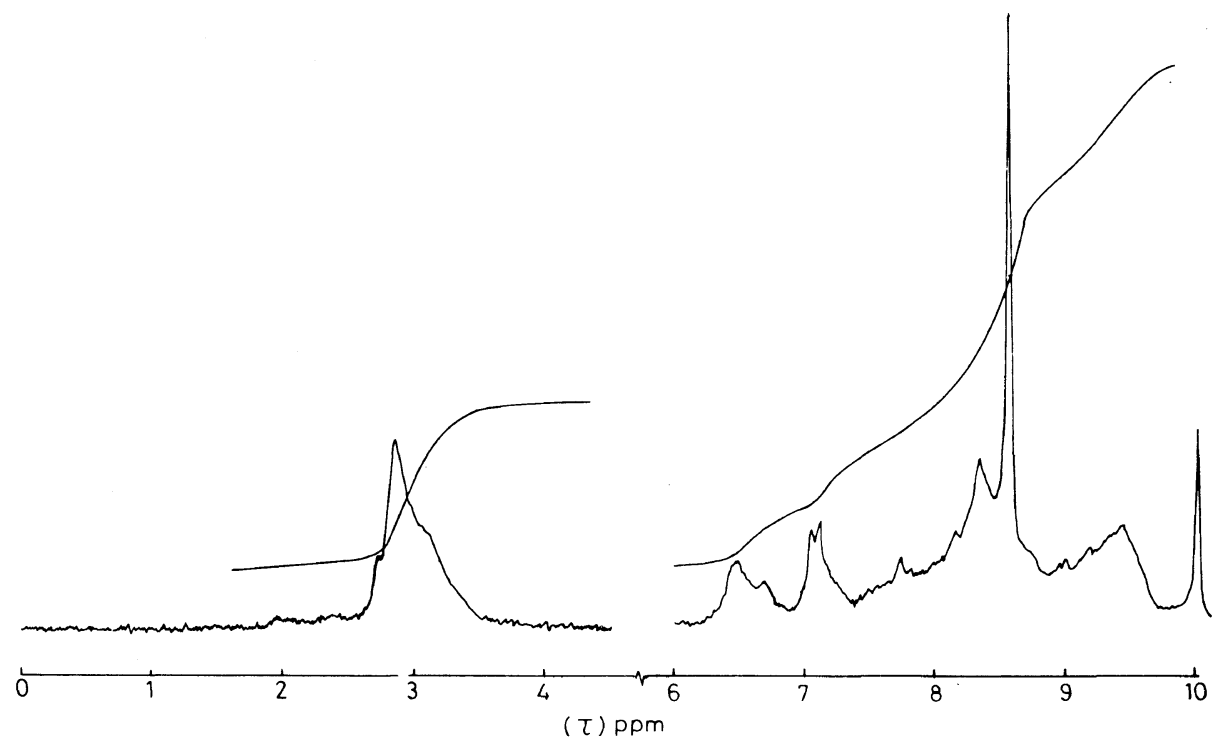

Figure 2. NMR spectrum of copolymer in $\mathrm{CDCl}_{3}$. [Ylide] $=14.0 \times 10^{-4} \mathrm{moll}^{-1} ;[\mathrm{MMA}]=1.08 \mathrm{moll}^{-1}$; $[\mathrm{St}]=1.38 \mathrm{moll}^{-1} ;$ time $=60 \mathrm{~min}$; temperature $=85^{\circ} \mathrm{C} \pm 0.1^{\circ} \mathrm{C}$.

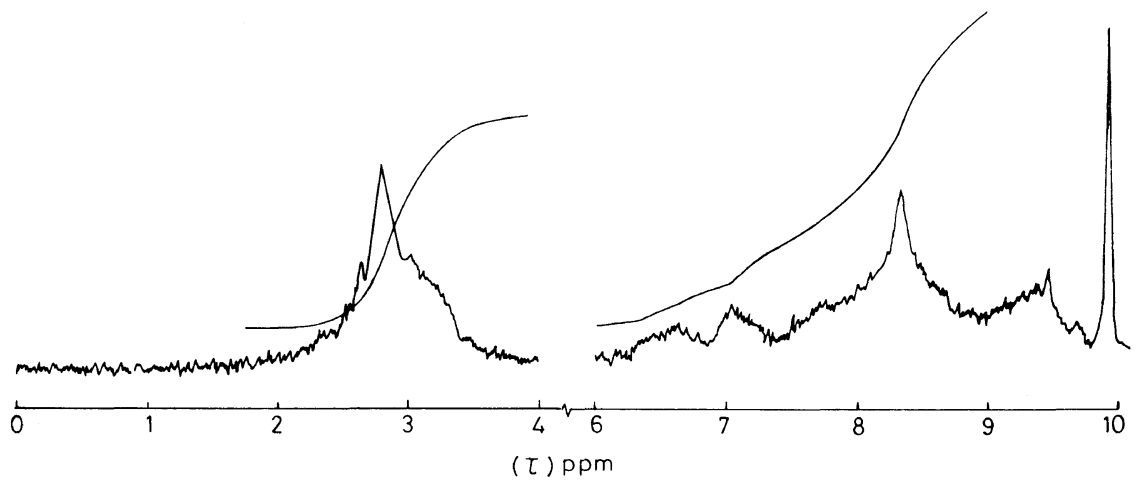

Figure 3. NMR spectrum of copolymer in $\mathrm{CDCl}_{3}$. [Ylide] $=14.0 \times 10^{-4} \mathrm{moll}^{-1} ;[\mathrm{MMA}]=1.44 \mathrm{moll}^{-1}$; $[\mathrm{St}]=1.02 \mathrm{moll}^{-1}$; time $=60 \mathrm{~min}$; temperature $=85^{\circ} \mathrm{C} \pm 0.1^{\circ} \mathrm{C}$.

reaction with respect to initiator, calculated from the slope of linear plot of $\log R_{\mathrm{p}} v s$. $\log$ [Ylide] is $0.5 \pm 0.02$ (Figure 1).

The average degree of polymerization of copolymers decreases with increasing initiator concentration, as expected for radical polymerization. The initiator exponent value and absence of an intercept in the plot of $1 / \bar{P}_{n} v s$. [Ylide] $^{0.5}$ suggest that free radical polymerization with bimolecular termination takes place.
The value of $k_{\mathrm{p}}^{2} / k_{\mathrm{t}}$, evaluated from slope of linear plot of $1 / \bar{P}_{n}$ vs. $R_{\mathrm{p}}$ is $8.0 \times 10^{-4}$ $1 \mathrm{~mol}^{-1} \mathrm{~s}^{-1}$.

\section{Effects of Monomers}

The effects of [Monomers] on the $R_{\mathrm{p}}$ have also been studied and the results are summarized in Tables II and III. The monomer exponent values calculated from the slope of linear plot of $\log R_{\mathrm{p}} v s . \log$ [Monomer] is unity for both MMA and St. 


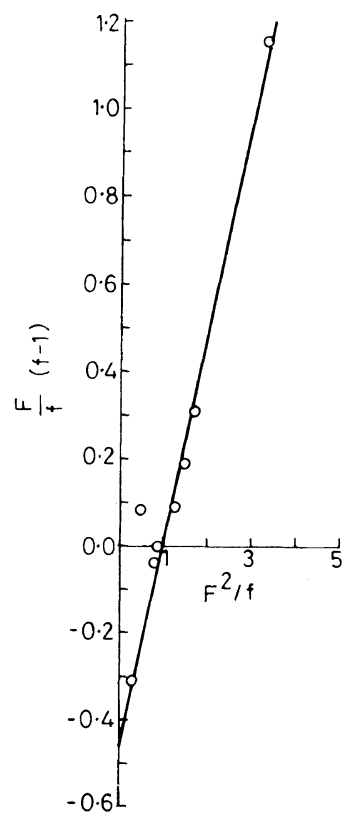

Figure 4. Finemann-Ross lower case.

$F=[\mathrm{St}] /[\mathrm{MMA}]$

$f=\mathbf{M}_{1} / \mathbf{M}_{2}$ where $M_{1}$ [St] and $\mathbf{M}_{2}$ [MMA] refer to the compositions of monomer in mole fractions calculated as from the NMR spectrum of the copolymer.

\section{Effects of Hydroquinone}

The initiator and monomer exponent values clearly suggest the radical mode of copolymerization, which is further confirmed by effects of hydroquinone on the copolymerization. The effects of hydroquinone have been studied by varying [hydroquinone] from $3.6 \times 10^{-3}$ moll $1^{-1}$ to $7.2 \times 10^{-3} \mathrm{moll}^{-1}$. For this change, $R_{\mathrm{p}}$ decreases from $5.4 \times 10^{-5} \mathrm{moll}^{-1} \mathrm{~s}^{-1}$ to $1.2 \times 10^{-5} \mathrm{moll}^{-1} \mathrm{~s}^{-1}$. The copolymerization was inhibited when [hydroquinone] was raised to $9.0 \times 10^{-3} \mathrm{moll}^{-1}$.

\section{Effects of Temperature}

The rate of copolymerization increases with increase in polymerization temperature. The energy of activation $(\Delta E)$ for the system, calculated from the linear Arrhenius plot is 96 $\mathrm{kJ} \mathrm{mol}^{-1}$.

\section{Structure and Composition}

NMR spectroscopy has been used to characterize the copolymers of styrene and MMA. The NMR spectra are shown in Figures 2 and 3 . There are five main resonance peaks observed. The singlet at $2.9-3.4 \tau$ is due to a phenyl proton of the styrene unit. The methyl protons appear at 9.2-9.6 , the methoxy protons at $6.4-6.8 \tau, 7.1-7.3 \tau$, and about $7.8 \tau$, which overlap in the region of 8.0 $8.8 \tau$ due to methylene and methyne protons. These three methoxy peaks are assigned ${ }^{11}$ to cosyndiotactic $(6.6 \tau)$, coheterotactic $(7.1 \tau)$, and coisotactic $(7.8 \tau)$ triad from low to high field. The appearance of methoxy protons as three splitted peaks suggests that the copolymer, prepared with the help of pyridinium dicyanomethylide has an alternating nature because in the case of random copolymers, the methoxy protons appear as a singlet peak at $6.38 \tau .{ }^{11}$ The relative areas due to phenyl protons of styrene and methoxy protons of MMA permit us to calculate copolymer composition.

\section{Reactivity Ratios}

The Finemann-Ross method ${ }^{12)}$ has been used to estimate the reactivity ratios from copolymer composition data.

The values of $r_{1}(\mathrm{St})$ and $r_{2}$ (MMA) (Figure 4) were found to be 0.46 and 0.45 , respectively, which match well with those reported in the literature ${ }^{13}$ thereby confirming alternating nature of the copolymers.

\section{CONCLUSIONS}

On the basis of the above discussion, it may be concluded that pyridinium dicyanomethylide can be used as a radical initiator to obtain an alternating copolymer of styrene and methyl methacrylate even in the absence of a Lewis acid.

Acknowledgements. The authors are thankful to Prof. A. K. Vasishtha, Director, 
H.B.T.I., Kanpur for providing the necessary facilities. One of the authors, Prerna Shukla, thanks C.S.I.R., New Delhi for awarding the Senior Research Fellow.

\section{REFERENCES}

1. S. Kondo, Muramatsu, M. Senga, and K. Tsuda, $J$. Polym. Sci., Polym. Chem. Ed., 22, 1187 (1984).

2. S. Kondo and K. Tsuda, J. Polym. Sci., Polym. Chem. Ed., 21, 217 (1983).

3. A. K. Srivastava, S. Saini, S. K. Nigam, and J. S. P. Rai, Eur. Polym. J., 23, 913 (1987).

4. S. K. Nigam and A. K. Srivastava, Acta Polymerica, 38, 242 (1987).

5. S. K. Nigam, S. Saini, and A. K. Srivastava, Indian J.
Tech., 24, 743 (1986).

6. S. K. Nigam, A. K. Shukla, S. Saini, P. Kumar, and A. K. Srivastava, Angew. Makromol. Chem., 149, 139 (1987).

7. P. Shukla and A. K. Srivastava, Eur. Polym. J., 24, 1115 (1988).

8. P. Shukla and A. K. Srivastava, Acta Polymerica, 40, 288 (1989).

9. W. J. Linn, O. Webster, and R. E. Benson, J. Am. Chem. Soc., 87, 3651 (1965).

10. A. K. Srivastava and G. N. Mathur, Polymer, 23, 391 (1982).

11. M. Hirooka, H. Yabuuchi, J. Iscki, and Y. Nakai, J. Polym. Sci., 6, 1381 (1968).

12. M. Fineman and S. D. Ross, J. Polym. Sci., 5, 259 (1950)

13. K. Ito and Y. Yamashita, J. Polym. Sci., Polym. Lett., 3, 625 (1965). 